\title{
Tradisi Pacu Itiak dalam Melestarikan Nilai-Nilai Budaya di Payakumbuh
}

Frea Purnama, Nurman

Program Studi Pendidikan Pancasila dan Kewarganegaraan

Universitas Negeri Padang

E-mail: freapurnama363@gmail.com

\section{ABSTRAK}

Tradisi pacu itiak salah satu tradisi yang di gemari oleh masyarakat di Kelurahan Aur Kuning Kecamatan Payakumbuh Selatan Kota Payakumbuh. Tradisi ini menimbulkan semacam pembelajaran nilai nilai budaya contohnya nilai kejujuran, patriotisme, persaingan, harmonis, kerjasama dan hiburan, nilai nilai ini berguna untuk dilestarikan. Kenyataannya pengunjung dan masyarakat tidak hanya menikmati lomba Pacu itiak sebagai ajang hiburan tetapi menjadikan lomba Pacu itiak sebagai arena judi dan taruhan. Penelitian ini bertujuan untuk mendeskripsikan nilai nilai tradisi Pacu itiak di kelurahan Aur Kuning Kecamatan Payakumbuh Selatan Kota Payakumbuh kemudian mendeskripsikan kendala-kendala dalam melaksanakan nilai-nilai budaya dalam tradisi Pacu itiak serta mendeskripsikan upaya yang dilakukan untuk melestarikan nilai-nilai budaya dalam tradisi pacu itiak. Penelitian ini menggunakan metode kualitatif dengan pendekatan deskriptif. Informan penelitian adalah niniak mamak, masyarakat, ketua Porti, Ketua galanggang dan ketua pemuda di Kelurahan Aur Kuning Kecamatan Payakumbuh Selatan Kota Payakumbuh. Bentuk dari nilai-nilai budaya dalam tradisi pacu itiak ini yaitu nilai harmonis, nilai kekeluargaan, nilai musyawarah dan nilai kompetisi/persaingan. Kendala-kendala dalam tradisi pacu itiak yakni terjadinya konflik antar peserta dan peserta dengan panitia dalam tradisi pacu itiak dan rendahnya kesadaran masyarakat dalam memaknai nilai-nilai yang terkandung. Upaya yang dilakukan untuk melestarikan nilai-nilai budaya dalam tradisi pacu itiak dengan cara ikut berpartisipasi apabila ada kegiatan dalam rangka pelestarian tradisi, menyosialisasikan kepada masyarakat bahwa tradisi pacu itiak ini merupakan fenomena unik yang patut untuk dijaga kelestariannya dan dipertahankan keasliannya. Penelitian ini menyimpulkan nilainilai yang terkandung dalam tradisi pacu itiak sudah terlaksana tetapi belum optimal..

Kata Kunci: tradisi, masyarakat, budaya, pacu itiak

\section{ABSTRACT}

The tradition of Pacu Itik that are one of the traditions favored by the community in the village of Aur Kuning District South Payakumbuh, Payakumbuh City. This tradition poses a kind of learning values of culture such as the value of honesty, patriotism, competition, harmoniously, cooperation and entertainment, the value of this value is useful to be preserved, the reality of visitors and community not only enjoy The pacu itiak is an amusement event but makes the Pacu itiak competition as a gambling arena and betting. This study aims to describe the value of the tradition in the village of Aur Kuning District South Payakumbuh, 
Payakumbuh City. Then to describe the constraints in implementing cultural values in the tradition of Pacu itiak and also to describes the efforts undertaken to preserve cultural values in the runway traditions in that village. This research uses qualitative methods with a descriptive approach. The research informant is NiniakMamak, community, chairman of Porti, head of the Galanggang and youth chair in AurKuningDistrictSouth Payakumbuh, PayakumbuhCity. The results of this research form the cultural values in the tradition of Pacu itiak is harmonious value, family value, deliberation value and the value of competition/competition. Obstacles in the tradition of Pacu itiak is the occurrence of conflicts between participants and participants with the committee in the tradition of the pacu itiak and low public awareness in the values that are contained in the tradition of the pacu itiak. Efforts undertaken to preserve cultural values in the tradition of the race by participating when there are activities in the framework of the preservation of traditions, socialize to the community that this tradition of ducks is a phenomenon That is worthy of its sustainability and retained authenticity. This research concludes that the values contained in the tradition of the race are already carried out but not optimal.

Keywords : traditions, society, culture, pacu itiak

This work is licensed under the Creative Commons Attribution-ShareAlike 4.0 International License. (2019 by author and Universitas Negeri Padang.

\section{PENDAHULUAN}

Tradisi pacu itik salah satu tradisi yang di gemari oleh masyarakat di Kota Payakumbuh. Tradisi ini menimbulkan semacam pembelajaran nilai nilai budaya contohnya nilai kejujuran, patriotisme, persaingan, harmonis, kerjasama dan hiburan, nilai nilai ini berguna untuk dilestarikan, kenyataan nya pengunjung dan masyarakat tidak hanya menikmati lomba Pacu itiak sebagai ajang hiburan tetapi menjadikan lomba Pacu itiak sebagai arena judi dan taruhan. Pandangan seperti itu bisa membuat nilai nilai budaya tradisi yang diwariskan secara turun temurun itu luntur dan sulit untuk dipertahankan apalagi pada era modernisasi yang krisis dengan nilai nilai budaya tradisi. - Ketertarikan penulis dengan tema artikel ini karena tradisi pacu itiak ini merupakan fenomena unik yang ada di Indonesia khususnya dikota Payakumbuh, untuk perlu dilestarikan dan harus dipertahankan keasriannya. Oleh karena itu penulis ingin menggali lebih dalam lagi mengenai Tradisi Pacu itiak Dalam Melestarikan Nilai-Nilai Budaya Di Payakumbuh.

Berdasarkan hasil penelitian terdahulu yang dilakukan oleh Rina (2017) menunjukan Masyarakat Jawa masih menjunjung tinggi nilai-nilai kebudayaan hal tersebut dibuktikan dengan masih banyaknya ritual-ritual yang masih mereka laksanakan sampai sekarang karna budaya Jawa merupakan salah satu kebudayaan yang dimiliki bangsa Indonesia yang di dalam tradisinya memiliki nilai-nilai keluhuran dan kearifan budaya yang menjadi ciri khas masyarakat Jawa. Hal serupa yang yang ditemukan dalam penelitian terdahulu oleh Soehardi (2002) tentang makna nilai- 
nilai budaya daerah yang sekiranya dapat menyumbang terbentuknya jatidiri bangsa atau identitas bangsa Indonesia dalam wacana globalisasi hubungan-hubungan antarbangsabangsa di dunia. Sesuai dengan arah pembahasan dalam tulisan ini dipusatkan pada tradisi lisan.

Begitu juga dengan penelitian Rizki (2015) memfokuskan pada pelaksanaan tradisi pacu jawi di Kab. Tanah datar yang dalam setiap tahapan nya terdapat nilai-nilai adat dan merupakan salah satu nilai kearifan lokal yang masih di wariskan orang Minangkabau dan masih di pertahankan sampai saat sekarang ini. Hal yang sama dengan penelitian Purnama (2014) lebih menfokuskan kepada daya tarik pacu jawi sebagai atraksi wisata budaya yang merupakan pamenan anak nagari (permainan menghibur dan menyampaikan nilai nilai luhur) Begitu juga dengan penelitian Amalia (2017) tradisi pacu kuda yang masih bertahan diantara lajunya arus perkembangan zaman, tradisi ini masih dilaksanakan tiap tahunnya oleh masyarakat Bener karna diyakini memiliki fungsi dan pengaruh terhadap kehidupan sosial masyarakat. Hal tersebut mempengaruhi kepercayaan masyarakat agar mempertahankan dan melestarikan tradisi tersebut.

Adapun perbedaan penelitian ini dengan penelitian yang relevan sebelumnya adalah penulis hanya mengemukakan bentuk nilai-nilai budaya, kedala kendala yang ada serta upaya dalam melestarikan tradisi Pacu itiak. Sedangkan penelitian yang relevan lainnya mengemukakan tentang topic yang berbeda tetapi memiliki tujuan yang sama yaitu tentang melestarikan nilai nilai yang terkandung dalam tradisi masing masing. Karena belum ada penelitian ilmiah yang membahas tentang tradisi Pacu itiak, untuk itu diperlukan sebuah upaya untuk mendokumentasikan tradisi Pacu itiak agar generasi muda berikutnya dapat melestarikan nilai-nilai tradisi Pacu itiak.

Lomba Pacu itiak dilakukan dilintasan sepanjang $1600 \mathrm{~m}$. Peseta lomba melepaskan itiak pada titik awal lomba, kemudian itiak terbang menuju garis finis. Di garis finish sudah ada juri yang menentukan itiak yang akan keluar sebagai juara berdasarkan itiak yang lebih dahulu mencapai garis finish. Adanya terjadi konflik antara peserta dan panitia dikarenakan harapan tidak sesuai dengan hasil, peserta ada yang tidak setuju dengan hasil yang di beritahu panitia dan peserta pun ada yang melakukan kecurangan-kecurangan seperti mendahului garis star, ada yang menusuk ekor itiak sebelum terbang supaya itiak bisa terbang kencang ke garis finis. Dengan ada nya kecurangan-kecurangan tersebut terjadinya persaingan yang tidak sehat demi untuk memenangkan Pacu itiak.

Keterbatasan solusi yang pernah ada yaitu Pemerintah dalam melestarikan tradisi Pacu itiak di Payakumbuh ini hanya untuk meningkatkan kunjungan pariwisata agar tradisi Pacu itiak ini bisa dikenal oleh banyakorang yang ada di Indonesia Kemudian kelebihan solusi yang ditawarkan dalam artikel ini adalah peneliti dalam melestarikan tradisi Pacu itiak ini adalah dengan menilah nilai-nilai yang ada dalam tradisi Pacu itiak ini dan meningkatkan kesadaran masyarakat 
dalam memaknai nilai-nilai yang terkandung dalam tradisi Pacu itiak.

Tujuan penelitian ini adalah untuk mendeskripsikan nilai-nilai tradisi Pacu itiak di Kota Payakumbuh. Serta dapat bermanfaat bagi masyarakat untuk mengetahui cara melestarikan kebudayaan Pacu itiak yang mengandung nilai-nilai budaya.

\section{METODE PENELITIAN}

Penelitian ini termasuk jenis penelitian kualitatif dengan menggunakan pendekatan deskriptif yang bertujuan untuk mendeskripsikan nilai-nilai tradisi Pacu itiak di Kota Payakumbuh . Teknik penentuan informan dalam penelitian untuk mengumpulkan data secara purposive sampling. Informan yaitu niniak mamak, masyarakat, ketua Porti, Ketua galanggang dan ketua pemuda di Kota Payakumbuh. Jenis data yang digunakan dalam penelitian ini adalah data primer dan data sekunder. Teknik yang digunakan adalah observasi, wawancara dan dokumentasi. Setelah data terkumpul, diolah dengan teknik analisis data melalui tahapan reduksi data, penyajian data dan penarikan kesimpulan dari data yang diperoleh. Waktu penelitian kurang lebih satu setengah bulan.

\section{HASIL DAN PEMBAHASAN}

Berdasarkan deskripsi, diperoleh nilai-nilai budaya dalam melestarikan tradisi pacu itiak. Hasil dan pembahasannya meliputi tentang nilai-nilai budaya dalam tradisi Pacu itiak di Payakumbuh, kendala-kendala dalam melaksanakan nilai-nilai budaya dalam tradisi Pacu itiak, serta upaya yang dilakukan untuk melestarikan nilai-nilai budaya dalam tradisi Pacu itiak di Payakumbuh.

1. Nilai-nilai budaya dalam tradisi pacu itik

Nilai-nilai budaya dalam tradisi Pacu itiak di Kota Payakumbuh adalah nilai harmonis, nilai kekeluargaan, nilai musyawarah serta nilai persaingan.

Dalam tradisi pacu itik ada dua nilai-nilai yang terkandung menurut oleh Akhmad Harum (2013) yang menyatakan nilai-nilai budaya yang berharga dan tetap dipertahankan,adalah:

(1) Nilai Kejujuran merupakan hal yang sangat penting dalam kehidupan masyarakat oleh karena itu setiap individu sejak dini harus dididik agar dapat menerapkan nilai kejujuran dalam hidupnya

(2) Nilai Patriotism dapat diartikan sebagai cinta tanah air dan semangat untuk kemakmuran tanah airnya, sleh karna itu nilai patriotism bagus ditanamkan untuk masyarakat,

(3) Nilai Persaingan yang dimaksud dengan nilai persaingan disini adalah nilai yang bersifat positif,

(4) Nilai Harmonis dan Kerjasama dalam kehidupan kita bermasyarakat, nilai harmionis dan kerjasama penting dimiliki oleh masyarakat tersebut.

2. Kendala-kendala dalam melaksanakan tradisi pacu itik

Dalam tradisi Pacu itiak ini terdapat kendala-kendala dalam melaksanakan nilai-nilai budaya. Karena, kurang adanya landasan dalam pemahaman tradisi Pacu itiak. Kendala-kendala tersebut diantaranya: a. Terjadi konflik antar peserta dan peserta dengan panitia dalam tradisi Pacu itiak. 
Konflik merupakan perselisihan yang terjadi antar individu atau antar kelompok dimana terjadinya konflik dikarenakan adanya perbedaan prinsip yang membuat suatu hubungan yang merenggang dan berakibat pertengkaran. Menurut Abdulsyani (2012: 158), pertikaian adalah bentuk persaingan yang berkembang secara negative, artinya disatu pihak bermaksud untuk mencelakakan paling tidak berusaha untuk menyingkirkan pihak lainnya. Sedangkan menurut Soedjono dalam Abdulsyani (2012: 158), pertikaian adalah suatu bentuk interelasi sosial dimana terjadi usaha-usaha pihak yang satu berusaha menjatuhkan pihak yang lain.

Dari hasil penelitian dalam tradisi Pacu itiak penulis tidak ada melihat adanya konflik, berbeda dengan hasil wawancara konflik dalam tradisi Pacu itiak disini terjadi karena salah satu peserta ada yang tidak tahan untuk mendahului star dan juri di finish langsung menetapkan nomor paruh itiak yang juara, yang seharus nya tidak juara atau di diskualifikasi tetapi peserta tersebut yang juara.

b. Rendahnya kesadaran masyarakat dalam memaknai nilainilai yang terkandung dalam tradisi Pacu itiak.

Dalam penelitian penulis terlihat rendahnya kesadaran masyarakat dalam memaknai nilai-nilai budaya yang ada dalam tradisi Pacu itiak seperti adanya taruhan dan konflik yang dilakukan antara sesama peserta dan antara peserta dengan panitia

3. Upaya yang dilakukan untuk melestarikan nilai-nilai tradisi pacu itik
Menurut Kathleen Liwidjaja (2007: 52) ada beberapa hal dalam upaya melestarikan tradisi, diantaranya a) partisipasi, partisipasi masyarakat adalah keikutsertaan dalam proses pengidentifikasian masalah dan potensi yang ada dalam maasyarakat, pemilihan dan pengambilan keputusan tentang alternative solusi untuk menangani masalah, pelaksanaan upaya mengatasi masalah dan keterlibatan masyarakat dalam mengevaluasi perubahan yang terjadi. b) Sosialisasi, sosialisasi dlam masyarakat dilakukan dengan memberikan materi dan infirmasi tentang tradisi. Sehingga dengan adanya sosialisasi ini dapat mengurangi terjadinya konflik dan mencegah perilaku menyimpang agar tidak menjadi budaya dalam masyarakat.

Jadi upaya yang dilakukan oleh masyarakat kelurahan Sawahpadang Aur Kuning untuk melestarikan dan menjaga keaslian tradisi Pacu itiak yaitu pertama ikut berpartisipasi apabila ada kegiatan dalam rangka pelestarian tradisi misalnya dengan cara mengikuti tradisi Pacu itiak dengan baik, kedua mensosialisasikan kepada masyarakat bahwa tradisi Pacu itiak ini merupakan fenomena unik yang patut untuk dijaga kelestariannya dan dipertahankan keasliannya karna tradisi Pacu itiak merupakan satusatunya yang ada diIndonesia.

Upaya yang dilakukan untuk melestarikan nilai-nilai budaya dalam tradisi ini ada upaya mensosialisasikan yang dilakukan agar masyarakat Kelurahan Sawahpadang Aur Kuning dapat melestarikan dan memaknai nilai-nilai budaya dalam tradisi Pacu itiak. Niniak mamak dan Panitia tradisi Pacu itiak mengumpulkan 
masyarakat dan para pemain yang akan ikut berpartisipasi dilapangan sebelum melaksanakan tradisi Pacu itiak sehingga tradisi Pacu itiak berjalan dengan baik tanpa adanya konflik.

\section{KESIMPULAN}

Berdasarkan hasil penelitian dan pembahasan tentang nilai-nilai budaya dalam melestarikan tradisi pacu itik di Kota Payakumbuh dapat diketahui bahwa nilai-nilai budaya dalam tradisi pacu itik ini sudah terlaksana dengan baik tapi belum optimal. Dalam penelitian terdapat kendala dalam melaksanakan nilai-nilai budaya tradisi pacu itik karena kurang adanya landasan dalam pemahaman tradisi pacu itik. Upaya yang dilakukan untuk melestarikan nilai-nilai budaya adalah dengan cara pertama ikut berpartisipasi apabila ada kegiatan dalam rangka pelestarian tradisi, kedua mensosialisasikan kepada masyarakat bahwa tradisi pacu itik ini merupakan fenomena unik yang patut untuk dijaga kelestariannya dan dipertahankan keasliannya karna tradisi pacu itik merupakan satusatunya yang ada diIndonesia.

Penelitian ini telah menekuni bidang ilmu yang sesuai dengan penelitian diantara nya hukum adat yang mana didalam ini membahas mengenai kebudayaan yaitu bentuk nilai-nilai budaya yang ada dalam tradisi Pacu itiak.

Implikasi artikel ini terhadap penelitian lainnya adalah dapat membantu peneliti dalam memahami tentang bentuk nilai-nilai budaya dalam tradisi Pacu itiak, serta penelitian ini memberikan bantuan kepada penelitian lain dalam mengetahui kendala kendala dan upaya dalam tradisi Pacu itiak.

Berdasarkan pada kesimpulankesimpulan yang diambil berkaitan dengan penelitian ini, maka penulis menyampaikan saran yang kiranya dilakukan dan bermanfaat bagi orang lain, diantaranya:

Untuk seluruh masyarakat, ninik mamak dan pemerintah, diharapkan ikut aktif dan terlibat dalam melestrikan nilai-nilai tradisi Pacu itiak di Kelurahan Aur Kuning Kecamatan Payakumbuh Selatan Kota Payakumbuh. Peniliti berharap pemerintah mengeluarkan dasar hukum tradisi Pacu itiak supaya tidak ada kecurangan-kecurangan dan konflik yang terjadi dalam pelaksanaan tradisi Pacu itiak. Sementara bagi Dinas pariwisata kalau memang untuk pengembangan pariwisata harus mengetahui dan memahami nilai-nilai budaya yang terkandung dalam tiap-tiap event wisata yang dikelola.

\section{DAFTAR PUSTAKA}

Amalia. (2017). Pacuan Kuda Dalam Kajian Sosiologi (Suatu Penelitian di Kabupaten Bener Meriah). Jurnal Ilmiah Mahasiswa FISIP Unsyiah. Vol2. Nol 2. Page 3

Harum, A. (2013). Analisis Materi Pendidikan dan Nilai-nilai Budaya. diakses tanggal 20 Desember 2018

Lividjaja, K. (2007). Komunikasi Keluarga. Jakarta: Rajawali Press Purnama. (2014). Daya Tarik Pacu Jawi sebagai Atraksi Wisata Budaya di Kabupaten Tanah Datar. Jurnal Nasional Pariwisata. Vol. 6.No.1.page2 
180 | tradisi pacu itiak..

Rizki. (2015). Kontruksi Makna dalam Upacara Adat Tradisi Pacu Jawi sebagai Kearifan local Kabupaten Tanah Datar Proponsi Sumatera Barat. Jurnal Buana. Vol 2. No 3. Page 4

Soehardi. (2002). Nilai-nilai Tradisi Lisan dalam Budaya Jawa. Jurnal Humaniora. Vol 14. No 3. Page 3

Syani, A. (2007). Sosiologi Skematika, Teori dan Terapan. Jakarta: Bumi Aksara.

Yesika, R. (2017). Nilai-nilai Religius yang Terkandung dalam Tradisi Perkawinan Adat Jawa. Jurnal Simki-padagogia. Vol 01, No 07.page 5 